\title{
Functional effects of a free jejunum flap used for reconstruction in the oropharyngeal region
}

\author{
Yukihiro Michiwaki ${ }^{1}$, Rainer Schmelzeisen ${ }^{2}$, Tamas Hacki ${ }^{3}$, Ken-ichi Michi ${ }^{1}$ \\ ${ }^{1}$ First Dept of Oral and Maxillofacial Surgery (Head: Prof. Ken-ichi Michi), School of Dentistry, Showa \\ University, Japan, ${ }^{2}$ Dept of Oral and Maxillofacial Surgery (Head: Prof. J.-E. Hausamen), Medical \\ University Hannover, ${ }^{3}$ Dept of Pedaudiology and Phoniatry (Head: Prof. E. Loebell), Medical University \\ Hannover, Germany.
}

$S U M M A R Y$. Postoperative articulatory function was assessed in $\mathbf{5}$ patients who had had radical operations for cancers of the oropharyngeal region with surgical reconstruction using free jejunum flaps. A patient with total resection of the soft palate had the lowest scores of $39.9 \% .4$ patients with less resection than total removal of the soft palate had good scores $(\mathbf{8 6 . 0} \%)$, and the articulatory dysfunction was limited only in plosive sounds produced in the velar region. A comparative study with glossectomized patients revealed that those who had had resection of the oropharynx achieved excellent articulation except for sounds produced in the velar region. The importance of operative function was stressed, to evaluate indications for the surgical technique for reconstruction of large tissue defects after ablation of head and neck cancers, and to improve the quality of life of those patients.

\section{INTRODUCTION}

Patients with advanced oral cancers have recently been treated by multimodal therapy in which ablative operation including resection of adjacent structures is the most important and successful procedure. After the ablation of a malignant tumor, however, a large tissue defect and functional incompetence might remain. In addition, the larger the resected area, the more difficult it is to repair the subsequent defect with surrounding tissue, and the more severe the postoperative functional damage. Surgical reconstruction, therefore, has been developed to correct such tissue defects and preclude postoperative dysfunction.

The reconstruction of large soft tissue defects can be accomplished by several techniques, such as a pectoralis major myocutaneous (PMMC) flap (Ariyan, 1979; Baek et al., 1982), a latissimus dorsi myocutaneous flap (Barton et al., 1983), a revascularized intestinal jejunum flap (Reuter et al., 1984), a free radial forearm flap (Soutar and McGregor, 1986) or a free composite groin flap (Salibian et al., 1990). These procedures are considered to be useful operations with acceptable clinical courses and few complications, but their functional effects have not been evaluated in depth, with the exception of a few reports (Kumakura, 1985; Salibian et al., 1990; Michiwaki et al., 1990, 1992). There is no clear agreement on the functional effect of these flaps.

The present study had two purposes: The first was to assess the postoperative articulation of patients who had been treated with surgical reconstruction using a free jejunum flap. The second was to identify site-specific problems by a comparative study of glossectomized patients.

\section{MATERIAL AND METHODS}

Five patients from the Department of Oral and Maxillofacial Surgery of the Medical School Hannover were the subjects for this study. The criteria for inclusion were: (1) the primary site of the malignant tumor was the retromolar or mesopharyngeal region; (2) the subjects had been operated on radically at least 6 months previously, with immediate reconstruction using a free jejunum flap without other adjunctive skin flaps. However, patients with mandibular reconstruction were included; (3) the resected area was

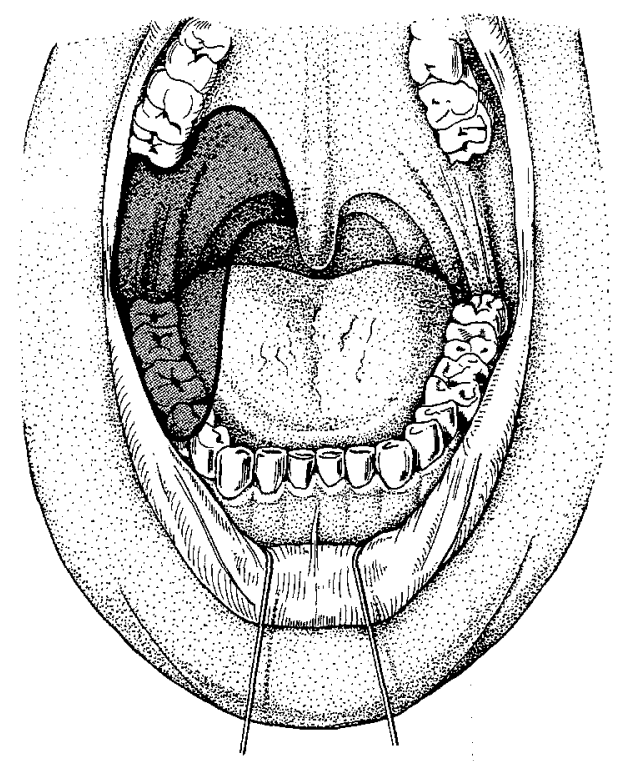

Fig. 1 - Schema of typical resection. 
Table 1 - Subjects

\begin{tabular}{|c|c|c|c|c|c|c|c|}
\hline No. & Sex & Age & TNM & $\begin{array}{l}\text { Time } \\
\text { lapse } \\
\text { (yrs) }\end{array}$ & $\begin{array}{l}\text { Extent } \\
\text { Tongue }\end{array}$ & $\begin{array}{l}\text { f resection } \\
\text { Soft } \\
\text { palate }\end{array}$ & Mandible \\
\hline $1 \dagger$ & M & 45 & $\mathrm{~T}_{4} \mathrm{~N}_{1} \mathrm{M}_{0}$ & 1.0 & Partial & Partial & Partial* \\
\hline 2 & M & 50 & - & 4.5 & - & Hemi & In continuity \\
\hline $3 \dagger$ & M & 63 & $\mathrm{~T}_{3} \mathrm{~N}_{2} \mathrm{M}_{0}$ & 2.5 & Partial & Hemi & Partial* \\
\hline 4 & M & 35 & 一 & 1.5 & - & Subtotal & —** \\
\hline 5 & $\mathrm{~F}$ & 42 & $T_{2} N_{1} M_{0}$ & 2.6 & Partial & Total & In continuity \\
\hline
\end{tabular}

+ Preoperative radiotherapy and chemotherapy

* In continuity resection of the mandible secondary to the primary operation

** Partial resection of the maxilla

the oropharyngeal region including the adjacent structures (Fig. 1) and (4) patients had no signs of recurrence or distant metastasis.

Table 1 presents the distribution of the patients by age, sex, TNM, and summary of the treatment. Concerning the extent of removal of the soft palate, two patients had resection of one-half, and partial, subtotal or total resection was performed in each patient. The extent of ablation of the tongue and the mandible or maxilla is also summarized in Table 1.

Speech function was assessed by a German articulation test, a new version of the Freiburger Audiometry Test (German Industrial Standard 45621), which contains 180 meaningful German monosyllables, as reported by Michiwaki et al. (1992). Five different samples of the test material were prepared to avoid repetition. Each patient chose one, and was asked to read each of the 180 monosyllables spaced at $3 \mathrm{~s}$ intervals. A tape of the articulation test was played back to five native German speakers, who were unfamiliar with the patients, and were asked to write down what they heard. Before the adjudication, to prevent prejudice in their judgment, they were informed that what they were about to hear might or might not be meaningful words.

Overall scores, and scores for manner and site of articulation were estimated. Based on the manner of production of initial consonants, 171 monosyllables with consonant + vowel (CV) or CVC combinations were divided into six groups: plosive, fricative, affricate, nasal, vibrant and lateral. Individual errors were assigned to their respective groups and scores for each group were calculated. According to the categories of site of articulation established by Wulff (1983) and the International Phonetic Association (IPA), the 171 words were divided into six groups: bilabial sounds, labio-dental sounds, linguo-alveolar sounds, linguo-palatal sounds, linguo-velar sounds, and glottal sounds. The scores for site of articulation were expected to indicate which site in the vocal tract was damaged for that particular function.

\section{RESULTS}

\section{Postoperative articulation of the patients}

The mean overall score was $76.8 \%$, ranging from 39.9 to $98.0 \%$ (Table 2). The patient with total resection of the soft palate (case 5) had the lowest overall score of $39.9 \%$, although overall scores of the others were satisfactory, ranging from 72.0 to $98.0 \%$. For manner of articulation (Table 2), plosive sounds scored $70.0 \%$, and other sounds scored over $80 \%$. The patient with total resection of the soft palate (case 5) had the lowest scores of all categories of sounds except vibrant and lateral sounds. Plosive sounds, in particular, scored poorly, $24.8 \%$.

For site of articulation (Table 3), all sound groups excepting velar sounds had excellent scores above $90 \%$. Sounds made in the velar region had the lowest score, $58.9 \%$. Case 5 also had the lowest scores of all classes of sounds, particularly for sounds produced in the velar region. Among the other 4 cases, two cases of squamous cell carcinoma had relatively poor scores of $30.9 \%$ and $59.1 \%$ for the velar sounds, though another two with mucoepidermoid carcinomas had excellent scores of $87.3 \%$ and $100 \%$. Case 2 , who had a mucoepidermoid carcinoma and had undergone the least amount of resection of the adjacent soft tissue around the soft palate, had the best overall scores of $98.0 \%$ and excellent scores for all sounds relevant to both categories, manner and site of articulation (Table 2, 3).

\section{Comparison between glossectomized patients and patients who had had the oropharynx resected}

The present authors reported the postoperative articulation of 18 glossectomized patients who had squamous cell carcinoma and underwent radical operations combined with immediate reconstruction using free jejunum flaps. The subjects were divided into three groups based on the site of the primary tumor: five patients with tongue tumors; six patients with tumors in the lateral part of the floor of the mouth; and seven patients with tumors of the anterior part of the floor of the mouth. The patients with tongue tumors had undergone hemiglossectomy or

Table 2 - Overall scores and scores for initial sounds based on manner of articulation

\begin{tabular}{llllllll}
\hline & $\begin{array}{l}\text { Overall } \\
\text { score }\end{array}$ & $\begin{array}{l}\text { Plosive } \\
(\%)\end{array}$ & $\begin{array}{l}\text { Fricative } \\
(\%)\end{array}$ & $\begin{array}{l}\text { Affricate } \\
(\%)\end{array}$ & $\begin{array}{l}\text { Nasal } \\
(\%)\end{array}$ & $\begin{array}{l}\text { Vibrant } \\
(\%)\end{array}$ & $\begin{array}{l}\text { Lateral } \\
(\%)\end{array}$ \\
\hline 1 & 87.0 & 80.3 & 96.2 & 95.0 & 100 & 100 & 100 \\
2 & 98.0 & 99.4 & 98.2 & 100 & 100 & 100 & 100 \\
3 & 72.0 & 64.2 & 80.6 & 95.0 & 93.3 & 83.6 & 100 \\
4 & 87.0 & 81.3 & 94.1 & 95.0 & 100 & 81.8 & 97.5 \\
5 & 39.9 & 24.8 & 50.6 & 60.0 & 81.7 & 89.1 & 100 \\
\hline$\overline{\mathrm{x}}$ & 76.8 & 70.0 & 83.9 & 89.0 & 95.0 & 90.9 & 99.5
\end{tabular}

Table 3 - Scores of the articulation test based on site of articulation

\begin{tabular}{llllccl}
\hline & $\begin{array}{l}\text { Bi- } \\
\text { labial } \\
\text { No. }\end{array}$ & $\begin{array}{l}\text { Labio- } \\
\text { dental } \\
(\%)\end{array}$ & $\begin{array}{l}\text { Linguo- } \\
\text { alveolar } \\
(\%)\end{array}$ & $\begin{array}{l}\text { Linguo- } \\
\text { palatal } \\
(\%)\end{array}$ & $\begin{array}{l}\text { Linguo- } \\
\text { velar } \\
(\%)\end{array}$ & $\begin{array}{l}\text { Glottal } \\
(\%)\end{array}$ \\
\hline 1 & 91.4 & 90.0 & 96.7 & 97.8 & 59.1 & 100 \\
2 & 99.1 & 94.0 & 99.4 & 100 & 100 & 100 \\
3 & 78.4 & 60.0 & 91.1 & 87.4 & 30.9 & 84.1 \\
4 & 71.6 & 81.0 & 93.3 & 100 & 87.3 & 97.7 \\
5 & 31.0 & 32.0 & 46.7 & 44.4 & 17.3 & 95.5 \\
\hline$\overline{\mathrm{x}}$ & 74.3 & 71.4 & 85.4 & 85.9 & 58.9 & 95.5
\end{tabular}


Table 4 - Comparison of postoperative articulation between glossectomees and patients with resection of the oropharynx

\begin{tabular}{lllllllll}
\hline $\begin{array}{l}\text { Site of } \\
\text { tumors }\end{array}$ & $\begin{array}{l}\text { No. } \\
(\mathrm{n})\end{array}$ & $\begin{array}{l}\text { Overall } \\
\text { score } \\
(\%)\end{array}$ & $\begin{array}{l}\text { Plosive } \\
(\%)\end{array}$ & $\begin{array}{l}\text { Fricative } \\
(\%)\end{array}$ & $\begin{array}{l}\text { Affricate } \\
(\%)\end{array}$ & $\begin{array}{l}\text { Nasal } \\
(\%)\end{array}$ & $\begin{array}{l}\text { Vibrant } \\
(\%)\end{array}$ & $\begin{array}{l}\text { Lateral } \\
(\%)\end{array}$ \\
\hline Oropharynx & 4 & 86.0 & 81.3 & 92.3 & 96.3 & 98.3 & 91.4 & 99.4 \\
Tongue & 5 & 91.4 & 90.7 & 96.9 & 91.5 & 99.3 & 97.1 & 96.5 \\
Lateral floor & 6 & 84.8 & 85.5 & 89.8 & 82.5 & 94.5 & 94.9 & 94.2 \\
Anterior floor & 7 & 63.4 & 60.8 & 81.3 & 68.6 & 89.5 & 82.6 & 75.7 \\
\hline
\end{tabular}

(All cases were reconstructed with free jejunum flaps)

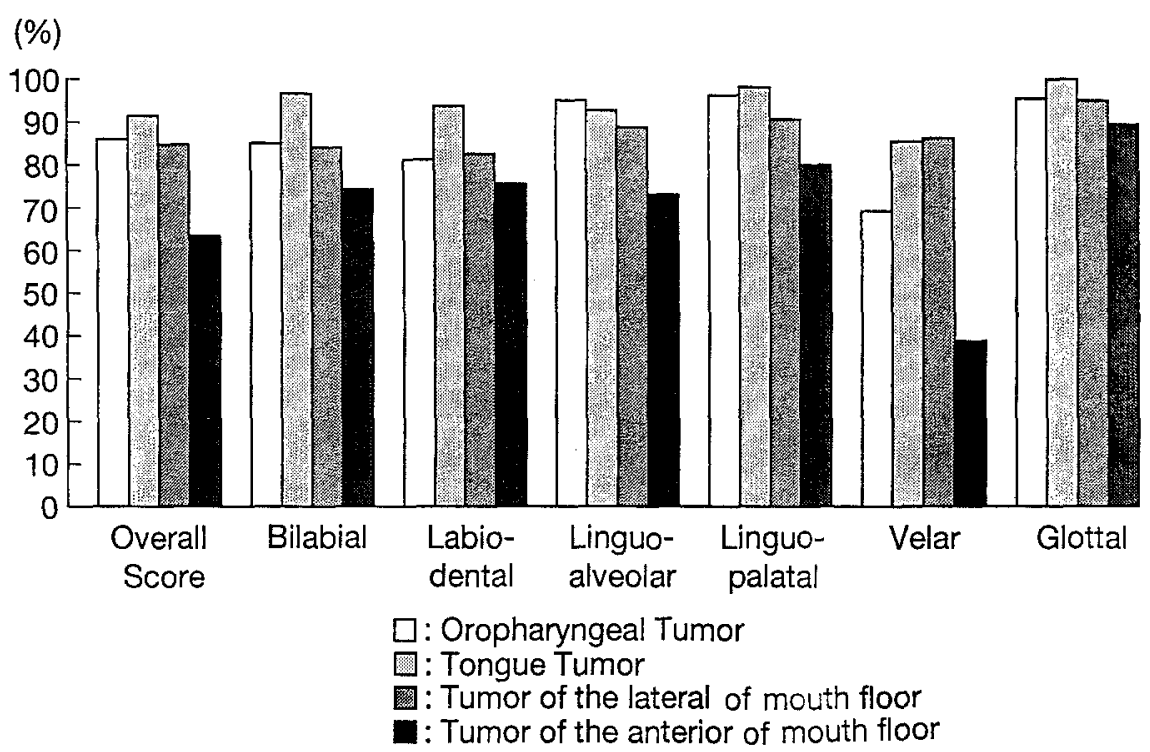

Fig. 2 - Comparison of postoperative articulation between gloosectomees and patients with resection of the oropharynx.

two thirds resection of the tongue with or without mandibulectomy. The patients with tumors of the lateral part of the floor of the mouth had had resection of an unilateral side of the tongue, whereas the anterior portion of both sides of the tongue was removed in patients with tumors of the anterior part of the floor of the mouth. Details of the extent of resection were demonstrated in a previous report (Michiwaki et al., 1992).

A comparative study was performed to examine the nature of articulatory distortion in relation to the site of operation. The group of glossectomies did not include patients with total glossectomy, therefore the case with total resection of the soft palate in the presence study was also excluded.

The mean overall score of the patients with tongue tumors was first, $91.4 \%$, and the mean overall score of patients with resection of the oropharynx was second, $86.0 \%$, which was almost equal to the mean score of patients with tumors of the lateral part of the floor of the mouth. In manner of articulation (Table 4), the patients with tumors of the lateral part of the floor of the mouth had slightly lower scores, $85.5 \%$ and $82.5 \%$ for plosives and affricates respectively; and the patients with tumors of the mesopharynx had scores under $90 \%(81.3 \%)$ for plosive sounds only. Scores of patients with tumors of the anterior part of the floor of the mouth were the lowest for all groups of sounds (Table 4).

Based on site of articulation (Fig. 2), the patients with tongue tumors and tumors of the lateral floor of the mouth had, on the whole, excellent scores for all classes of sounds. The patients with tumors of the oropharynx had obviously low scores, $69.3 \%$, for velar sounds, but had excellent scores for other classes of sounds, comparable to the scores of the patients with the tongue tumors and tumors of the lateral portion of the floor of the mouth. The patients with tumors of the anterior part of the floor of the mouth had the lowest overall scores and also for all categories of consonants.

\section{DISCUSSION}

Studies of glossectomized patients have proved that postoperative function depends on many factors, including the site of resection, the amount of the tissue defect, time lapse after the operation, and treatment modality (Rentscher et al., 1980; Kumakura 1985; Salibian et al., 1990; Teichgraeber et al., 1986; Michiwaki et al., 1990, 1992). To ascertain superiority in relieving the postoperative functional impairment by the various reconstructive techniques, the contributing factors should be the same in each case. Thus there are few cases in a single hospital that can be compared for postoperative function. Accordingly, it is proposed that many institutes should cooperate in evaluating postoperative functions of their individual patients, using an objective and consistent system for assessment. If many cases with the same contributing factors could be gathered to compare the functional 
effects of different methods of reconstruction, it would provide some help in determining the indications for each reconstructive technique.

In the present study, speech function was evaluated using an articulation test for the following reasons: the estimation of articulation is quantitative, usually presented as a percentage, and articulatory distortion can be analyzed in detail based on manner and site of articulation, and then the result can be utilized for further improvement in operative procedures and speech rehabilitation. We think that the articulation test is suitable for assessing techniques postoperatively from the view of preventing postoperative functional impairment.

The present study revealed that a jejunum flap is effective in precluding articulatory dysfunction except for the patient with total resection of the soft palate. The other 4 patients achieved adequate speech function except for sounds produced in the velar region, $/ \mathrm{k} /$ and $/ \mathrm{g} /$. The mean of scores for $/ \mathrm{k} /$ and $\mathrm{g} /$ in those 4 cases was $68.9 \%$ and the mean score for $/ \mathrm{p} /, / \mathrm{b} /, / \mathrm{d} /$ and $/ \mathrm{t} /$ was $86.5 \%$. Thus, the low scores for $/ \mathrm{k} /$ and $/ \mathrm{g} /$ do not result from velopharyngeal incompetence but from loss of functional integrity in the oropharyngeal region.

After total resection of the soft palate including the lateral wall of the oropharynx, no intrinsic tissue remains to close the velopharynx, resulting in severe velopharyngeal incompetence (case 5). There are some treatment methods to obtain better velopharyngeal closure, such as a pharyngeal flap operation and prosthodontic appliances. Those methods seem to be useful, if performed together with the transfer of a jejunum flap after total resection of the soft palate.

A comparative study among 18 glossectomized patients and four patients with resection of the oropharyngeal region clarified the site-specific problem of postoperative articulation. The articulatory function of patients with resection of the mesopharynx was, on the whole, consistent with that of patients who had cancers of the tongue or lateral part of the floor of the mouth. The articulatory dysfunction of patients with mesopharyngeal resection was limited only to those plosive sounds produced in the velar region, the area operated on.

Ohno et al. (1992) reported on the postoperative articulation in 3 patients who had had surgical reconstruction using free radial forearm flaps to correct extensive tissue loss after ablation of an oropharyngeal cancer. The extent of resection of the soft palate was one half in 2 cases and subtotal in one. Overall scores of the patients were $40.8 \%, 70.2 \%$ and $74.2 \%$. Based on the manner of articulation, scores for plosive sounds were poor, $32.6 \%, 58.2 \%$ and $72.2 \%$ respectively. Comparing the result with those in the present study, patients with free jejunum flaps had significantly better scores, not only for overall scores, but for all categories of sounds. The comparison suggested that a jejunum flap was more effective for the relief of articulatory impairment in patients who had undergone radical operation in the oropharyngeal region. The reasons why the jejunum flap resulted in better articulation were considered to be the reduced scar formation and intrinsic pliability, which did not restrict mobility of adjacent structures, as reported by Reuter et al. (1984).

\section{Acknowledgement}

The authors thank the Alexander von Humboldt-Foundation in Germany for financial support for the present study.

\section{References}

Ariyan, S.: Further experiences with the pectoralis major myocutaneous flap for the immediate repair of defects from excisions of head and neck cancers. Plast. Reconstr. Surg. 64 (1979) 605-612

Baek, S. M., W. Lawson, H. F. Biller: An analysis of 133 pectoralis major myocutaneous flaps. Plast. Reconstr. Surg. 69 (1982) 460-469

Barton, F. E. Jr., T. E. Spicer, H. S. Byrd: Head and neck reconstruction with the latissimus dorsi myocutaneous flap: Anatomical observation and report of 60 cases. Plast. Reconst. Surg. 71 (1983) 199-204

Kamakura, I.: A study of speech intelligibility after glossectomyAnalysis of 60 tongue cancer cases. Jpn. J. Logop. Phoniatr. 26 (1985) 224-235

Michiwaki, Y., K. Ohno, S. Imai, Y. Yamashita, N. Suzuki, H. Yoshida, K. Michi: Functional effects of intraoral reconstruction with a free radial forearm flap. J. Cranio-Max.Fac. Surg. 18 (1990) 164-168

Michiwaki, Y., R. Schmelzeisen, T. Hacki, K. Michi: Articulatory function in glossectomized patients with immediate reconstruction using a free jejunum flap. J. Cranio-Max.-Fac. Surg. 20 (1992) 203-210

Ohno, K., A. Nakamura, Y. Yamashita, T. Ohsawa, K. Mori, Y. Michiwaki, H. Akizuki, K. Saitoh, H. Yoshida, K. Michi: Application of reconstruction with the free radial forearm flap and speech aid appliance for the soft palate and oropharyngeal defects. J. Jpn. Stomatol. Soc. 41 (1992) 401-413

Rentscher, G.J., A. Arbor, M. B. Mann: The effects of glossectomy on intelligibility of speech and oral perceptual discrimination. J. Oral Surg. 38 (1980) 348-354

Reuther, J. F., H.-U. Steinau, R. Wagner: Reconstruction of large defects in the oropharynx with a revascularized intestinal graft: An experimental and clinical report. Plast. Reconstr. Surg. 73 (1984) 345-358

Salibian, A. M., G. R. Allison, I. Rappaport, M. E. Krugman, B. L. McMicken, T. L. Etchepare: Total and subtotal glossectomy Function after microvascular reconstruction. Plast. Reconstr. Surg. 85 (1990) 513-524

Soutar, D. S., I. A. McGregor: The radial forearm flap in intraoral reconstruction: The experience of 60 consecutive cases. Plast. Reconstr. Surg. 78 (1986) 1-8

Teichgraeber, J., J. Bowman, H. Goepfert: Functional analysis of treatment of oral cavity cancer. Arch Otolaryngol Head Neck Surg. 112 (1986) 959-965

Wulff, $H$.: Diagnostik der Sprach und Stimmbehinderunge. In: Diagnose von Sprach- und Stimmstoerungen. Ernst Reinhardt, Muenchen 1983, p. 44.

Yukihiro Michiwaki, DDS, PhD

First Dept. of Oral and Maxillofacial Surgery

School of Dentistry, Showa University

2-1-1 Kitasenzoku Ohta-ku Tokyo, 145 Japan

Paper received 15 September 1992

Accepted 4 December 1992 